\title{
Post-treatment surveillance abdominopelvic computed tomography in children with Wilms tumour: Is it worth the risk?
}

\author{
Authors: \\ Jacobus H. Otto ${ }^{1}$ \\ Jacques Janse van Rensburg \\ David K. Stones ${ }^{2}$

\begin{abstract}
Affiliations:
${ }^{1}$ Department of Clinical of the Free State, South Africa
\end{abstract} \\ Imaging Sciences, University \\ ${ }^{2}$ Paediatric Haematology and \\ Oncology, Department of \\ Paediatrics and Child Health, \\ University of the Free State, \\ South Africa

\section{Correspondence to:} \\ Jacobus Otto \\ Email: \\ flipotto@gmail.com \\ Postal address: \\ 4 Kipling Street, Dan Pienaar, \\ Bloemfontein 9301, South \\ Africa \\ Dates: \\ Received: 02 Feb. 2015 \\ Accepted: 15 May 2015 \\ Published: 05 Aug. 2015 \\ How to cite this article: \\ Otto JH, Janse van Rensburg, \\ J, Stones DK. Post-treatment \\ surveillance abdominopelvic \\ computed tomography in \\ children with Wilms tumour: \\ Is it worth the risk?. S Afr J \\ Rad. 2015;19(1); Art. \#784, \\ 6 pages. http://dx.doi. \\ org/10.4102/sajr.v19i1.784

\section{Copyright:} \\ (C) 2015. The Authors. \\ Licensee: AOSIS \\ OpenJournals. This work is \\ licensed under the Creative \\ Commons Attribution \\ License.
}

Background: Wilms tumour is a comparatively common paediatric malignancy with a relatively good prognosis. Routine post-treatment surveillance at our institution currently includes regular abdominopelvic computed tomography (CT) over a two-year period for the early detection of disease recurrence. The rationale is that early salvage therapy may improve overall patient survival, and thus justifies the exposure to potentially harmful ionising radiation.

Objective: To critically evaluate the routine use of post-treatment abdominopelvic CT by determining the detection rate of disease recurrence and associated clinical outcomes.

Methods: Sixty-four patients in remission following initial treatment for Wilms tumour were included in this retrospective study. Variables obtained from patient records included gender, age, histological grading and tumour stage at presentation, number of abdominopelvic CT scans, site(s) of relapse, method of recurrence detection and confirmation, time to recurrence and clinical outcome.

Results: The patients received a total of 334 surveillance abdominopelvic CT scans. Nine (14\%) patients developed disease recurrence during the follow-up period. In three cases, the initial detection method was abdominopelvic CT. All three of these patients subsequently died despite salvage therapy (22 months median survival). Five false-positive diagnoses of recurrence occurred, with two being made on abdominopelvic CT.

Conclusion: Routine post-treatment abdominopelvic CT showed a low detection rate of disease recurrence in children treated for Wilms tumour, while subjecting patients to a large radiation burden. The recommendation is that current practice be changed in line with the ultrasound-based Société Internationale d'Oncologie Pédiatrique (SIOP) imaging guidelines.

\section{Introduction}

Wilms tumour (nephroblastoma) is the second most common intra-abdominal tumour presenting during childhood, with approximately $80 \%$ of cases diagnosed before the age of 5 years. ${ }^{1}$ Advances in treatment have greatly improved the prognosis for children with this condition. Where survival rates were once less than $30 \%$, they are currently quoted at $90 \%$, making it one of the success stories of modern medicine. ${ }^{2}$

Nephroblastomas metastasise predominantly to the lungs (58\%) and liver (29\%), and only rarely to other sites such as the skeleton, mediastinum and brain. Most relapses (90\%) occur within 4 years of diagnosis. ${ }^{3}$ The practice of post-treatment surveillance imaging is aimed at the early detection of tumour recurrence, thereby enabling early salvage therapy. Long-term survival following salvage therapy has reportedly increased from below 30\% in the mid-1980s, to the current range of $50 \%-60 \%{ }^{4}$

Recommendations for post-treatment surveillance imaging of patients with Wilms tumour that are currently in use include the guidelines proposed by the American COG (Childhood Oncology Group) (Table 1) and European Société Internationale d'Oncologie Pédiatrique (International Society of Paediatric Oncology) (SIOP) (Table 2). These imaging recommendations were originally created for research purposes, but are often used to guide the clinical use of imaging studies. As far as could be determined, no other standardised guidelines have been published. ${ }^{1}$

The Universitas Academic Hospital Paediatric Oncology Unit in Bloemfontein, South Africa, follows the SIOP guidelines to stage and manage patients who have been diagnosed with Wilms 
TABLE 1: COG recommendations for CT as part of off-therapy surveillance imaging in Wilms tumour. ${ }^{5}$

\begin{tabular}{llll}
\hline Disease group & Region & Imaging modality & Frequency \\
\hline Very low risk & $\begin{array}{l}\text { Chest } \\
\text { Abdomen/pelvis }\end{array}$ & $\begin{array}{l}\mathrm{CT} \\
\mathrm{CT} \text { or MRI }\end{array}$ & $\begin{array}{l}\text { End of therapy, then every } 2 \text { months } \times 3, \text { then every } 3 \text { months } \times 4 \\
\text { End of therapy, then every } 2 \text { months } \times 3 \text {, then every } 3 \text { months } \times 4 ; \text { then } \\
\text { change to abdominal ultrasound }\end{array}$ \\
Low and standard risk stage I-III & $\begin{array}{l}\text { Chest } \\
\text { Abdomen/pelvis }\end{array}$ & $\begin{array}{l}\text { CT } \\
\text { CT or MRI }\end{array}$ & $\begin{array}{l}\text { End of therapy, then every } 6 \text { months to } 3 \text { years (alternating with chest X-ray) } \\
\text { End of therapy, then every } 6 \text { months for } 3 \text { years }\end{array}$ \\
Higher risk favourable histology & Chest & CT & End of therapy, then every 3 months $\times 8$ \\
& Abdomen/pelvis & CT or MRI & End of therapy, then every 3 months $\times 8$; then change to ultrasound \\
\hline
\end{tabular}

COG, Childhood Oncology Group; CT, computed tomography; MRI, magnetic resonance imaging.

TABLE 2: SIOP imaging recommendations for long-term follow-up of children with renal neoplasms. ${ }^{6}$

\begin{tabular}{|c|c|c|}
\hline Patient group & Investigation & Frequency after stopping therapy \\
\hline \multirow[t]{2}{*}{ Non-metastatic disease at diagnosis } & Chest X-ray & $\begin{array}{l}\text { 1st and } 2 \text { nd year: every } 3 \text { months } \\
\text { 3rd year: every } 6 \text { months }\end{array}$ \\
\hline & Abdominal ultrasound & $\begin{array}{l}\text { At the end of treatment } \\
1 \text { and } 5 \text { years after stopping therapy }\end{array}$ \\
\hline Nephrogenic rests (any stage) & Abdominal ultrasound & 3 -monthly $\times 8$, then 6 -monthly $\times 6$, then annually $\times 5$ \\
\hline \multirow[t]{2}{*}{$\begin{array}{l}\text { Metastatic disease in complete remission after } \\
\text { stopping therapy }\end{array}$} & Chest X-ray & $\begin{array}{l}\text { 1st and } 2 \text { nd year: } 2 \text {-monthly } \\
\text { 3rd year: 6-monthly }\end{array}$ \\
\hline & Abdominal ultrasound & $\begin{array}{l}\text { At the end of treatment } \\
1 \text { and } 5 \text { years after stopping therapy }\end{array}$ \\
\hline Irradiated patients & X-ray bony structures & Annually to full growth: spine \pm pelvis, then every 5 years \\
\hline Bilateral tumours & Chest $\mathrm{X}$-ray and abdominal ultrasound & $\begin{array}{l}\text { 1st and } 2 \text { nd year: } 2 \text {-monthly } \\
\text { 3rd and 4th year: } 3 \text {-monthly } \\
\text { 5th to } 10 \text { th year: } 4 \text {-monthly }\end{array}$ \\
\hline Partial nephrectomy & Abdominal ultrasound & 3 -monthly $\times 8$, then 6 -monthly $\times 6$, then annually $\times 5$ \\
\hline
\end{tabular}

tumour. The imaging protocol for off-treatment surveillance is, however, largely based on the COG guidelines. Routine surveillance abdominopelvic computed tomography (CT) scans are performed at three-month intervals during the first year and six-monthly in the second year of post-treatment follow-up. Concurrent radiographs or CT of the chest are performed to screen for pulmonary metastases.

According to the COG guidelines, patients with high-risk Wilms tumours may receive up to 8 abdominopelvic CT scans during the post-treatment follow-up period. ${ }^{1}$ The estimated cumulative effective dose to an individual patient from all the ionising diagnostic radiological investigations performed at diagnosis, while on treatment, and during the follow-up period - according to the COG trials - amounts to $152.8 \mathrm{mSv},{ }^{5}$ which is the equivalent of approximately 7500 chest radiographs. ${ }^{7}$

The possible long-term adverse effects of low-dose radiation associated with radiological investigations are increasingly being put under the spotlight, with the most worrisome risk being that of radiation-induced cancer. ${ }^{8}$ The paediatric population is particularly susceptible to the harmful effects of ionising radiation owing to the increased radiosensitivity of their rapidly dividing cells, in particular thyroid, breast and gonadal tissue. Children also have a longer lifetime during which radiation-related cancers have time to develop. ${ }^{7}$

Compared with an adult, a dose of radiation results in a tenfold increase in neoplastic potential in a growing child. ${ }^{9}$ The estimated lifetime risk of radiation-induced fatal cancer in children who have had a CT scan is 1 in $1000 . .^{10}$ There is also an incremental increase in cancer risk for each additional CT scan. ${ }^{11}$ Paediatric oncology patients are often exposed to a large number of serial and frequently high-dose examinations, resulting in a considerable cumulative radiation exposure.

To justify the risk, albeit small, of radiation-induced malignancy owing to exposure from a radiological surveillance programme, two conditions have to be met. Firstly, disease recurrence has to be accurately detected before it becomes clinically apparent; and secondly, earlier detection of relapse should lead to improved overall survival. ${ }^{5}$

The aim of the present study was to critically evaluate the use of abdominopelvic CT scans in the post-treatment surveillance programme of children with Wilms tumour, with the purpose of effective minimisation of exposure to ionising radiation and optimal utilisation of limited resources. Our objectives were, firstly, to determine the radiological, and specifically abdominopelvic CT, detection rate of tumour recurrence during the routine surveillance programme in children who have successfully completed their treatment for nephroblastoma; and secondly, to determine the value of a positive radiological finding of recurrent disease by describing the clinical outcomes in these children.

\section{Methods}

A retrospective descriptive study was undertaken after obtaining approval from the Ethics Committee of the Faculty of Health Sciences, University of the Free State. Patients who had been treated for Wilms tumour and followed up at the Paediatric Oncology Unit at Universitas Academic Hospital between January 2000 and December 2012 were included. Further inclusion criteria included a clinical and radiological diagnosis of complete disease remission at the completion of treatment, as well as completion of the two-year period of routine off-treatment imaging surveillance. Patients who 

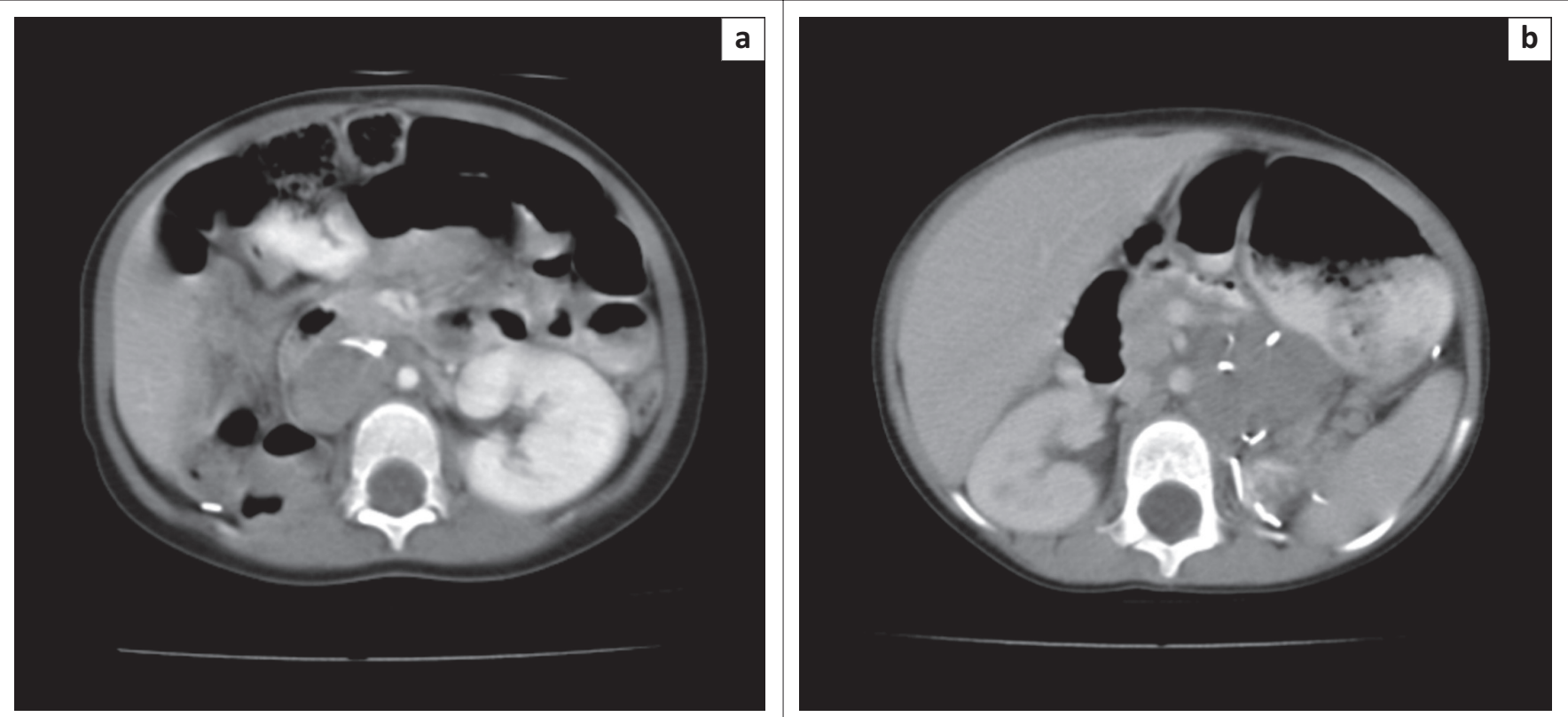

Source: Figure provided by authors.

FIGURE 1: Abdominopelvic CT in two patients with local recurrence of nephroblastoma, in the right kidney bed (a), and in the left kidney bed (b). Both patients subsequently developed disease progression and died.

had residual or progressive disease at the end of treatment, absconded from treatment or follow-up, or had died owing to comorbidities or other causes during the follow-up period, were excluded from the study population.

The variables collected from paper and electronic patient records included age at diagnosis, gender, initial tumour staging and histological grading, and the total number of abdominopelvic CT scans, including the number of surveillance scans. In the event of disease relapse during follow-up, the time between treatment completion and relapse, the anatomical site(s) of relapse, initial method of relapse detection and the method of confirming or refuting the diagnosis of relapse, were recorded. The last known clinical outcome for each patient was also established.

A total of 126 patients were treated for Wilms tumour during the period under investigation. Of these, 22 patients were lost to follow-up and 9 absconded. A further 31 patients were excluded owing to progressive or residual disease after completing the standard treatment protocol.

\section{Results}

Of the 64 patients included in the study population, there were slightly more girls $(n=35)$ than boys $(n=29)$. The median age at diagnosis was 3 years (range 0.6 to 11 years). The majority of patients $(61 \%, n=64)$ had SIOP stage I disease. Data on histological tumour grading was lacking in $42 \%(27 / 64)$ of patients, especially in those diagnosed before 2005. Of those with known histological grading, 81\% (30/37) had grade 2 or intermediate-grade tumour histology.

The patients included in the study population received a total of 479 abdominopelvic CT scans (mean of 7.5 per patient) during the process of disease staging, treatment monitoring and surveillance. A total of 334 surveillance abdominopelvic CT scans were done, with a mean of 5.2 scans per patient.

Nine patients ( $14 \%$ of the study population) had confirmed disease relapse during the follow-up period. The characteristics of these patients are set out in Table 3. The median time interval between completion of treatment and the diagnosis of relapse was 6 months (range 3-12 months). The most common anatomical site of relapse was the lungs $(56 \%, n=9)$, followed by local recurrence and liver metastases, both occurring in one-third of cases of relapse. No disease recurrence was found in the pelvis. One patient presented clinically with skeletal metastasis during the follow-up period.

Of the 9 confirmed cases of relapse, 3 were initially detected by surveillance abdominopelvic CT (Figure 1). A further 3 were detected by plain chest radiography, 1 by chest CT, and 2 presented with clinical symptoms of relapse.

The clinical outcomes in the patients who presented with relapse following disease remission were very discouraging. Eight of the 9 patients responded poorly to salvage therapy and died. The median duration of survival following the diagnosis of disease recurrence was 18 months (range 7-27 months). The only patient who could be successfully salvaged presented with lung metastases detected initially by chest radiograph.

In 5 patients diagnosed with disease relapse during the period of imaging surveillance, it was found not to be the case on subsequent biopsy or clinical and radiological follow-up. Of these false-positive cases, 2 were diagnosed 
TABLE 3: Characteristics and outcomes of cases $(n=9)$ with recurrence of Wilms tumour.

\begin{tabular}{|c|c|c|c|c|c|c|c|}
\hline \multirow[t]{2}{*}{ Patient } & \multirow[t]{2}{*}{ SIOP stage } & \multirow[t]{2}{*}{ Histological grade } & \multicolumn{5}{|c|}{ Tumour recurrence } \\
\hline & & & Site & Detection method & Time (months) ${ }^{\dagger}$ & Outcome & Survival (months) \\
\hline 1 & 1 & Unavailable & Lungs & Chest CT & 7 & Died & 27 \\
\hline 2 & 1 & Unavailable & Liver & Clinical & 3 & Died & 7 \\
\hline 3 & 1 & Intermediate risk & Bone & Clinical & 7 & Died & 7 \\
\hline 4 & 1 & Unavailable & Local, liver & Abdominopelvic CT & 12 & Died & 26 \\
\hline 5 & 4 & Unavailable & Local & Abdominopelvic CT & 5 & Died & 21 \\
\hline 6 & 1 & Unavailable & Lungs, liver & Chest radiograph & 6 & Died & 6 \\
\hline 7 & 1 & Intermediate risk & Lungs & Chest radiograph & 11 & Died & 14 \\
\hline 8 & 1 & Intermediate risk & Local, lungs & Abdominopelvic CT & 4 & Died & 22 \\
\hline 9 & 1 & Intermediate risk & Lungs & Chest radiograph & 6 & In remission & $\mathrm{N} / \mathrm{A}$ \\
\hline
\end{tabular}

$\mathrm{CT}$, computed tomography

time period between completion of treatment and detection of disease recurrence.

time period between detection of disease recurrence and death.

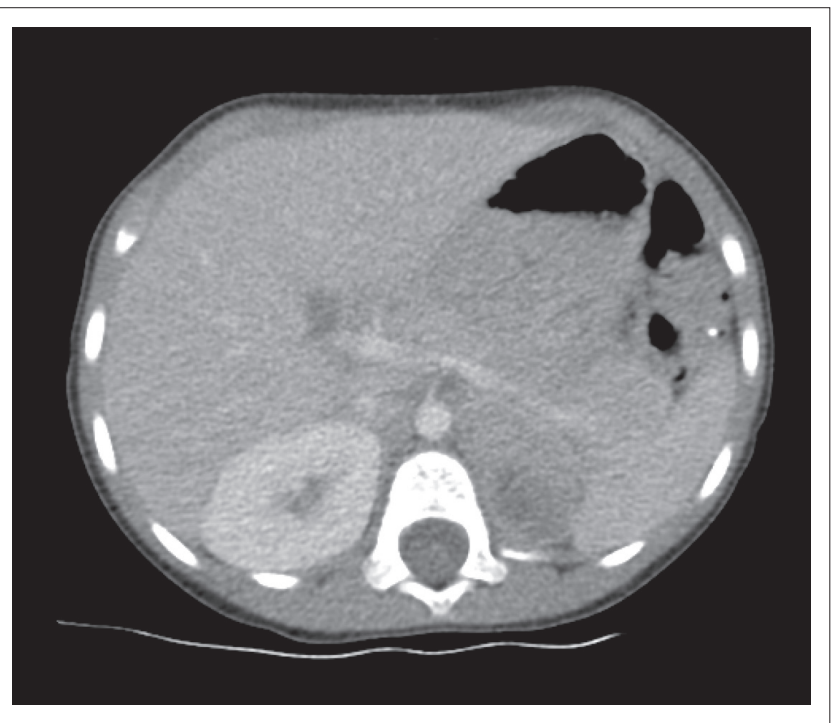

Source: Figure provided by authors.

FIGURE 2: Surveillance abdominopelvic CT showing a soft-tissue density in the left kidney bed, not present on a previous follow-up scan, incorrectly interpreted as local recurrence of nephroblastoma. A follow-up CT, done one month later, confirmed this as unopacified small bowel. The patient was still in remission two years later.

on abdominopelvic CT, 2 on chest CT and 1 on a chest radiograph (Figures $2-3$ ).

\section{Discussion}

Our rate of detecting disease recurrence with routine surveillance abdominopelvic CT was one recurrence for every 111 scans performed, which is similar to that found in a study by Howell et al., ${ }^{12}$ where routine CT detected one recurrence for every 129 scans performed in the follow-up of children with solid tumours. In their study, only $30 \%$ of the total recurrences were detected by routine investigations, with the majority presenting symptomatically between routine clinic appointments. This finding led the investigators to question the usefulness of frequent routine follow-up investigation in paediatric oncology. ${ }^{12}$ In contrast, the majority of relapses in our study were detected by imaging investigations, which may be attributed to differences between the natural history of Wilms tumour and the other solid tumours included in the study by Howell et al., ${ }^{12}$ the different frequency of routine

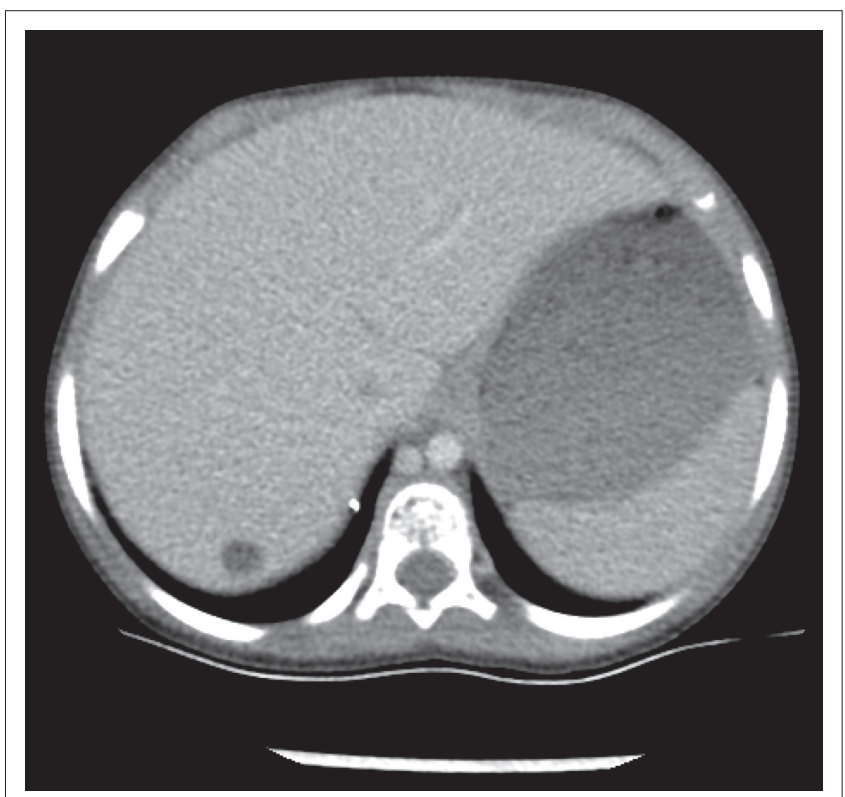

Source: Figure provided by authors.

FIGURE 3: Follow-up abdominopelvic CT in a patient, previously in remission following treatment for stage II nephroblastoma, shows a well-defined hypodense lesion in the right lobe of the liver. This lesion was not present on baseline imaging and had increased in size compared with a previous followup CT, making the lesion highly suggestive of a liver metastasis. The patient subsequently underwent liver resection. Histology revealed hydatid disease.

follow-up investigations, and the relatively small patient populations of both studies.

A few studies have evaluated the outcomes of the detection of disease relapse by routine surveillance imaging following completion of therapy for paediatric cancers. Most indicate little or no improvement in salvage rates between relapses detected by imaging or clinically. ${ }^{13}$ The salvage rates were equally dismal in relapses detected clinically or by imaging in our study. All 3 of our patients with disease recurrence detected by abdominopelvic CT, developed progressive disease and died regardless of salvage therapy, with a median survival of 22 months (range 21-26 months).

The ALARA (as low as reasonably achievable) principle advocates the reduction of radiation exposure through the optimisation of scanning parameters, the elimination of unnecessary examinations and the use of alternative 
non-ionising imaging modalities. Ways of decreasing the radiation exposure of a CT scan include optimising scan settings according to patient size and limiting the area of the body being scanned. Studies by Kaste et al. ${ }^{14}$ and Kan et al. $^{2}$ found no benefit from including the pelvis in routine surveillance CT of patients with Wilms tumour. Omitting pelvic CT saves an average of $30 \%$ to $45 \%$ of the effective dose of abdominopelvic CT. ${ }^{14}$ No pelvic recurrences were observed in our study population, further supporting these findings.

The elimination of unnecessary investigations and the use of alternative non-ionising imaging modalities constitute the most effective ways of reducing radiation exposure. The use of ultrasound in the initial diagnosis of Wilms tumour is well established. Renal ultrasonography is also considered the optimal screening modality for the detection of Wilms tumour in at-risk individuals. ${ }^{15}$ There are to our knowledge, however, no studies that compare the diagnostic performance of abdominal ultrasound with abdominopelvic CT in routine off-treatment surveillance. Daw et al. ${ }^{16}$ investigated abdominal relapse in Wilms tumour and found that all cases of recurrence were detected by ultrasound obtained at the time of relapse. Their results suggest that regular sonographic surveillance for three years after completion of treatment is likely to detect most abdominal recurrences, ${ }^{16}$ making it an attractive alternative to abdominopelvic CT.

The cost-effectiveness of routine follow-up investigations should also be taken into consideration, especially within the context of resource constraints. Guadagnolo et al. ${ }^{17}$ analysed the cost-effectiveness of CT in the routine followup of patients with Hodgkin's disease, comparing it with non-CT modalities. Their study also took into account the decrement in quality-adjusted life expectancy owing to falsepositive CT results. It was found that annual follow-up CT is associated with minimal survival benefit. For advanced stage patients, annual CT for 5 years was associated with a small quality-adjusted survival gain over non-CT follow-up, but at an incremental cost-effectiveness ratio of \$US9 million per quality-adjusted life year gained. ${ }^{17}$ The poor outcomes of patients with recurrence detected by abdominopelvic CT in our study, as well as the morbidity and anxiety associated with false-positive results, suggest an unfavourable costbenefit ratio for the use of this modality in the routine posttreatment surveillance of Wilms tumour.

To promote a more rational approach to follow-up imaging in children with cancer, it is important to understand the motivation of the different role players. The good treatment response of certain childhood cancers, including Wilms tumour, leads to optimistic attempts to achieve permanent control at any price. The difference in attitude of paediatric oncologists, compared with adult oncologists, also leads to a more aggressive approach to post-treatment surveillance. ${ }^{18}$ Ultimately, it remains the responsibility of the radiologist to ensure that any request for an imaging investigation is justified and that exposure to ionising radiation be kept as low as reasonably achievable.
Although it may be argued that the parents or the patients themselves derive reassurance from negative routine followup investigations, these may also lead to unnecessary anxiety, practical inconvenience and physical discomfort related to preparation for CT scans and intravenous contrast administration.

\section{Limitations of the study}

The study was limited by the relatively small study population. A large number of patients were excluded owing to poor treatment response associated with advanced disease at presentation, or were lost to follow-up. These circumstances compare poorly with the $90 \%$ remission rates reported in developed countries, and can most likely be attributed locally to poor socioeconomic conditions, low levels of education and a sub-optimally functioning primary healthcare system.

\section{Conclusion}

Our study set out to critically evaluate the routine use of abdominopelvic CT in the post-treatment surveillance of patients with Wilms tumour. We found that in the past 12 years, routine abdominopelvic CT detected only 3 cases of disease recurrence. Unfortunately, none of these patients survived much longer than 2 years following the diagnosis of disease recurrence, despite salvage therapy. At the same time, patients who did not go on to develop disease recurrence were subjected to a significant radiation burden, with the associated risk of radiation-induced cancer later in life.

In view of the findings, we propose the use of the SIOP surveillance imaging recommendations, using ultrasound in preference to CT for abdominal surveillance. This will lead to a significant reduction in radiation exposure and cost, without jeopardising patient outcomes.

Our findings highlight the need for improved and ongoing collaboration between paediatric oncologists and radiologists to re-assess current practices and devise optimised imaging strategies that take the risks associated with potentially avoidable exposure to ionising radiation, as well as the impact on limited resources, into account.

\section{Acknowledgements}

The authors thank Mr Cornel van Rooyen, Department of Biostatistics, Faculty of Health Sciences, University of the Free State, for his contribution to the study design and statistical analysis of the data; and Dr Daleen Struwig, medical writer, Faculty of Health Sciences, University of the Free State, for technical and editorial preparation of the manuscript.

\section{Competing interests}

The authors declare that they have no financial or personal relationships which may have inappropriately influenced them in writing this article. 


\section{Authors' contributions}

J.J.v.R. (University of the Free State) was the study leader; J.H.O. (University of the Free State) was responsible for originating the research question, the study design, data collection and writing of the research article; and D.K.S. (University of the Free State) made conceptual contributions, assisted with the process of data collection and critically evaluated the intellectual content of the final written manuscript.

\section{References}

1. Davidoff AM. Wilms' tumour. Curr Opin Pediatr. 2009;21:357-364. http://dx.doi. org/10.1097/MOP.0b013e32832b323a

2. Kan JH, Hwang M, Lowas SR, Hernanz-Schulman M. Impact of pelvic $\mathrm{CT}$ on staging, surveillance, and survival of pediatric patients with Wilms tumour and hepatoblastoma. Am J Roentgenol. 2011;196:W515-W518. http://dx.doi. org/10.2214/AJR.10.5179

3. Brisse HJ, Smets AM, Kaste SC, Owens $\mathrm{CM}$. Imaging in unilateral Wilms tumour. Pediatr Radiol. 2008;38:18-29. http://dx.doi.org/10.1007/s00247-007-0677-9

4. Metzger ML, Dome JS. Current therapy for Wilms tumour. Oncologist. 2005;10:815-826. http://dx.doi.org/10.1634/theoncologist.10-10-815

5. McHugh K, Roebuck DJ. Pediatric oncology surveillance imaging: Two recommendations. Abandon CT scanning, and randomize to imaging or solely clinical follow-up. Pediatr Blood Cancer. 2014;61:3-6. http://dx.doi.org/10.1002/pbc.24757

6. International Society of Paediatric Oncology (SIOP). Nephroblastoma Clinical Trial and Study SIOP 2001. c2007 [cited 30 January 2015]. Available from: http:// web.visu.uni-saarland.de/rtsg/fileadmin/templates/logistix/files/SIOP_Interim_ Statistical_Report.pdf
7. Brody AS, Frush DP, Huda W, Brent RL, American Academy of Pediatrics Section on Radiology. Radiation risk to children from computed tomography. Pediatrics. 2007;120:677-682. http://dx.doi.org/10.1542/peds.2007-1910

8. Voss SD, Reaman GH, Kaste SC, Slovis TL. The ALARA concept in pediatric oncology. Pediatr Radiol. 2009;39:1142-1146. http://dx.doi.org/10.1007/s00247-009-1404-5

9. Shah NB, Platt SL. ALARA: Is there cause for alarm? Reducing radiation risks from computed tomography scanning in children. Curr Opin Pediatr. 2008;20:243-247. http://dx.doi.org/10.1097/MOP.0b013e3282ffafd2

10. Brenner D, Elliston C, Hall E, Berdon W. Estimated risks of radiation-induced fatal cancer from pediatric CT. Am J Roentgenol. 2001;176:289-296. http://dx.doi. org/10.2214/ajr.176.2.1760289

11. Mathews JD, Forsythe AV, Brady ZB, et al. Cancer risk in 680000 people exposed to computed tomography scans in childhood or adolescence: Data linkage study of 11 million Australians. BMJ. 2013;346:f2360. http://dx.doi.org/10.1136/bmj. f2360

12. Howell L, Mensah A, Brennan B, Makin G. Detection of recurrence in childhood solid tumours. Cancer. 2005;103:1274-1279. http://dx.doi.org/10.1002/cncr.20896

13. Kaste SC. Oncological imaging: Tumour surveillance in children. Pediatr Radiol. 2011;41(Suppl 2):505-508. http://dx.doi.org/10.1007/s00247-011-2108-1

14. Kaste SC, Brady SL, Yee B, et al. Is routine pelvic surveillance imaging necessary in patients with Wilms tumour? Cancer. 2013;119:182-188. http://dx doi. org/10.1002/cncr.27687

15. Scott RH, Walker $L$, Olsen $\varnothing \mathrm{E}$, et al. Surveillance for Wilms tumour in at-risk individuals: Pragmatic recommendations for best practice. Arch Dis Child. 2006;91:995-999. http://dx.doi.org/10.1136/adc.2006.101295

16. Daw NC, Kauffman WM, Bodner SM, Pratt CB, Hoffer FA. Patterns of abdominal relapse and role of sonography in Wilms tumour. Pediatr Hematol Oncol. 2002;19:107-115. http://dx.doi.org/10.1080/08880010252825696

17. Guadagnolo BA, Punglia RS, Kuntz KM, Mauch PM, Ng AK. Cost-effectiveness analysis of computerized tomography in the routine follow-up of patients after primary treatment for Hodgkin's disease. J Clin Oncol. 2006;24:4116-4122. http:// dx.doi.org/10.1200/JCO.2006.07.0409

18. Kagan AR, Steckel RJ. Diagnostic imaging in the surveillance of treated children with cancer. Med Pediatr Oncol. 1993;21:323-326. http://dx.doi.org/10.1002/ mpo.2950210503 